\title{
Synthesis of novel AuPd nanoparticles decorated one-dimensional ZnO nanorod arrays with enhanced photoelectrochemical water splitting activity
}

\author{
Yan Lu ${ }^{\mathrm{a}, \mathrm{b}}$, Junlong Zhang ${ }^{\mathrm{b}}$, Lei Ge* a, ${ }^{\text {, }}$, Changcun Han ${ }^{\mathrm{b}}$, Ping Qiu ${ }^{\mathrm{b}}$, Siman Fang ${ }^{\mathrm{b}}$ \\ ${ }^{a}$ State Key Laboratory of Heavy Oil Processing, College of Science, China University of Petroleum Beijing, No. \\ 18 Fuxue Rd., Beijing 102249, People's Republic of China. \\ ${ }^{\mathrm{b}}$ Department of Materials Science and Engineering, College of Science, China University of Petroleum Beijing, \\ No. 18 Fuxue Rd., Beijing 102249, People's Republic of China.
}

\begin{abstract}
The vertically aligned one-dimensional (1D) $\mathrm{ZnO}$ nanorod arrays decorated with AuPd alloy nanoparticles have been synthesized with $\mathrm{ZnO}$ nanorod arrays as template via a mild hydrothermal method. In this work, the as-prepared $\mathrm{AuPd} / \mathrm{ZnO}$ nanorod arrays demonstrated high light-harvesting efficiency. The microstructures, morphologies and chemical properties of the obtained $\mathrm{AuPd} / \mathrm{ZnO}$ composite photocatalysts were investigated by scanning electron microscopy (SEM), X-ray diffraction (XRD), transmission electron microscopy (TEM), UV-vis diffuse reflectance spectra (DRS) and X-ray photoelectron spectroscopy (XPS). The photoelectrochemical (PEC) performances of as-obtained $\mathrm{AuPd} / \mathrm{ZnO}$ nanorod arrays were examined, and the photocurrent density was up to $0.98 \mathrm{~mA} \cdot \mathrm{cm}^{-2}$ at $0.787 \mathrm{~V}$ versus $\mathrm{Ag} / \mathrm{AgCl}$, which was about 2.4 times higher than the pure $\mathrm{ZnO}$ sample. A possible photocatalytic mechanism of the $\mathrm{AuPd} / \mathrm{ZnO}$ hybrid nanostructures under the simulated sunlight irradiation was proposed to guide further improvement of other desirable materials. In light of the above experiment results, it can be clearly found that $\mathrm{AuPd} / \mathrm{ZnO}$ composite nanorod arrays showed excellent PEC performance and have promising applications in the utilization of solar energy.
\end{abstract}

Keywords: AuPd alloy nanoparticles; ZnO nanorod arrays; photocurrent density; photocatalyst.

* Corresponding author at: State Key Laboratory of Heavy Oil Processing, China University of Petroleum Beijing, No. 18 Fuxue Road, Beijing102249, PR China. Tel/Fax.: +86 1089739096. E-mail address: gelei08@sina.com（L.Ge） 


\section{Introduction}

In response to the emergence of energy crisis and environmental problems, numerous semiconductor materials have attracted considerable attention to solve the energy and environment issues by energy conversion and the degradation of organic pollutants [1-5]. Hydrogen energy is considered as an ideal candidate to replace the traditional fossil energy to solve the above mentioned issues due to its sustainability, renewability and cleanliness [6-7]. Among various technologies of manufacture hydrogen, photoelectrochemical (PEC) water splitting into hydrogen and oxygen via semiconductor photoelectrodes is one of the most promising strategies [8-9]. To date, 1D ZnO nanorod arrays have garnered considerable attention among several semiconductor photocatalysts because of its numerous advantages, such as low cost, nontoxicity, high electron mobility property and larger surface area [10-13]. However, the performances of bare $\mathrm{ZnO}$ nanorod arrays are limited due to its large band gap $(3.37 \mathrm{eV})$, quick recombination of photo-generated electron-hole pairs and photocorrosion, which hamper its extensive applications [14-15].

To solve these problems, great efforts have been devoted to improving the photocatalytic performance of $1 \mathrm{D} \mathrm{ZnO}$ nanorod arrays, such as sensitizing with other semiconductor (for instance $\mathrm{ZnS}$, $\mathrm{Ag}_{2} \mathrm{~S}, \mathrm{CdS} / \mathrm{PbS}$ ) [16-18], noble metal doping ( $\left.\mathrm{Au}, \mathrm{Ag}\right)$ [19-21]. It is known from many reports that various bimetallic alloy nanoparticles (such as AgPd, AuPt, PtNi) deposition could improve catalytic performances compared to monometallic nanoparticles due to the size effect and the unique microstructures [22-24]. Nevertheless, as far as we know, there is only a few reports on PEC electrodes of vertically one-dimensional $\mathrm{ZnO}$ nanorod arrays decorated with AuPd alloy nanoparticles. Combination of $\mathrm{Au}$ and $\mathrm{Pd}$ is an interesting possibility to achieve a catalyst with higher activity and to better understand the nature of the outstanding activity of Au containing catalysts [25]. So, it is worth exploring the superiority of bimetallic nanoalloys relative to a single component. Hence, to further 
evaluate the synergistic effect between $\mathrm{Au}$ and $\mathrm{Pd}$, we report the preparation of $\mathrm{AuPd} / \mathrm{ZnO}$ nanorod arrays catalyst.

In this work, we have synthesized the $\mathrm{AuPd} / \mathrm{ZnO}$ nanorod arrays for the first time and applied it in the area of photoelectrochemical water splitting under AM $1.5 \mathrm{G}$ sunlight irradiation. It can be clearly seen from TEM images that AuPd alloy nanoparticles were uniformly dispersed on $1 \mathrm{D} \mathrm{ZnO}$ nanorods which can enhance the PEC performance. The photocurrent density of $\mathrm{AuPd} / \mathrm{ZnO}$ photocatalyst is 0.98 $\mathrm{mA} \cdot \mathrm{cm}^{-2}$ at $0.787 \mathrm{~V}$ versus $\mathrm{Ag} / \mathrm{AgCl}$, which is about 2.4 times higher than pure $\mathrm{ZnO}$ nanorod arrays, revealing that bimetallic nanoparticles have greater potential in the utilization of free and inexhaustible solar energy.

\section{Experimental}

\subsection{Synthesis of $1 \mathrm{D} \mathrm{ZnO}$ nanorod arrays}

All chemical reagents which used in our experiment were without any purification. The $1 \mathrm{D} \mathrm{ZnO}$ nanorod arrays were prepared on the substrate of fluorine doped tin oxide (FTO) glass via a simple hydrothermal method as reported in previous literature with some modifications [26]. The experimental process includes the formation of $\mathrm{ZnO}$ seed layer and the hydrothermal growth procedure of $\mathrm{ZnO}$ nanorods in a mixing solution. This two-step process can effectively control the nanorod shape, size, density and orientation [27]. Prior to prepare the seed layer of $\mathrm{ZnO}$, FTO glass substrates was ultrasonically cleaned in deionized water, acetone and absolute ethanol two times respectively and each time for $15 \mathrm{~min}$.

The $0.5 \mathrm{ml}$ zinc nitrate solution $(0.5 \mathrm{M})$ and a desirable amount of equivalent concentration of hexamethylenetetramine (HMTA) were uniformly added to FTO substrates. A few minutes later, precipitation would be produced after the reaction of mixed solutions and subsequent spin coating, then the modified substrates via the annealing process at $200{ }^{\circ} \mathrm{C}$ for $10 \mathrm{~min}$. The above procedure should be 
repeated for 4 times in order to obtain an even and high density seed layer. The seeded substrate was put into a Teflon lined stainless-steel autoclave which contained the mixture solution of $0.05 \mathrm{M}$ zinc nitrate and the equal amount of HMTA $(0.05 \mathrm{M})$ to grow $1 \mathrm{D} \mathrm{ZnO}$ nanorod arrays at $90{ }^{\circ} \mathrm{C}$ for $5.5 \mathrm{~h}$. The obtained products were rinsed with deionized water and absolute ethanol three times, and then dried at $60{ }^{\circ} \mathrm{C}$ in the air.

\subsection{Synthesis of AuPd/ZnO photocatalyst}

The AuPd alloy nanoparticles were prepared by using a simple process which employed a reducing agent to reduce $\mathrm{Au}^{3+}$ and $\mathrm{Pd}^{2+}$ simultaneously as detailed in a previous reported literature [28]. Herein, we prepared AuPd alloy nanoparticles under a mild condition in which $\mathrm{NaBH}_{4}$ was selected as reductant. In a typical procedure, $0.01 \mathrm{M} \mathrm{HAuCl}_{4} \cdot 3 \mathrm{H}_{2} \mathrm{O}$ and $\mathrm{PdCl}_{2}$ aqueous solution were first prepared. Fresh aqueous solutions of $0.1 \mathrm{M} \mathrm{NaBH}_{4}$ and $1 \mathrm{wt} \%$ PVA were also prepared in advance. The $470 \mu \mathrm{PdCl}_{2}$ $(0.01 \mathrm{M})$ and $250 \mu \mathrm{HAuCl}_{4}(0.01 \mathrm{M})$ stock solution were mixed and the required amount $(1 \mathrm{wt} \%)$ of PVA solution was added $\left(\mathrm{PVA} /(\mathrm{Au}+\mathrm{Pd})=1.2\right.$, weight ratio), the fresh $\mathrm{NaBH}_{4}$ solution $\left(\mathrm{NaBH}_{4} /(\mathrm{Au}+\mathrm{Pd})\right.$ $=5$, molar ratio) was then added to form a dark-brown solution. The above solution was continuously stirred. Then pre-synthesized 1D ZnO nanorod arrays were immersed in above AuPd alloy solution for $40 \mathrm{~min}$ at room temperature. The sample was washed with ethanol then dried at $150{ }^{\circ} \mathrm{C}$ for $30 \mathrm{~min}$. Then the $\mathrm{AuPd} / \mathrm{ZnO}$ composite samples were obtained.

\subsection{Characterization}

The morphologies of the fabricated samples were analyzed with field emission scanning electron microscopy (SEM, FEI Quanta 200F; accelerating voltage $=10 \mathrm{kV}$ ). The crystal structure and phase of the pure $\mathrm{ZnO}$ were investigated using X-ray diffraction (XRD; Bruker D8 Advance, X-ray diffractometer) with $\mathrm{Cu} \mathrm{K} \alpha$ radiation. Transmission electron microscopy (TEM, JEM-2100, accelerating voltage $200 \mathrm{kV}$ ) and high-resolution transmission electron microscopy (HRTEM) were performed to 
reveal the nanostructure and composition of the as-prepared $\mathrm{AuPd} / \mathrm{ZnO}$ catalyst. The UV-Vis diffuse reflection spectroscopy (DRS) was performed on a Shimadzu UV-4100 spectrophotometer using $\mathrm{BaSO}_{4}$ as the reference material. The purpose of DRS was to investigate the optical absorption spectra (solar light harvesting properties) of the photoanodes. X-ray photoelectron spectroscopy (XPS) measurements were undertaken on a PHI 5300 ESCA system to detect the compositions of the as-prepared samples. The binding energies were corrected by the XPS signal of C1s.

\subsection{Characterization of photoelectrochemical performances}

Photoelectrochemical (PEC) characterization of the samples were performed using an electrochemical workstation (CHI660E), a three-electrode configuration, in which the $\mathrm{ZnO}$ nanorods and $\mathrm{AuPd} / \mathrm{ZnO}$ composite catalysts were employed to be the working photoelectrode, the saturated $\mathrm{Ag} / \mathrm{AgCl}$ and a platinum foil were used as reference and counter electrode, respectively. The whole photoelectrochemical tests were completed in $0.5 \mathrm{M}$ sodium sulfate electrolyte solution. The solar simulated incident light (AM $1.5 \mathrm{G}$ ) with the intensity is $100 \mathrm{~mW} \cdot \mathrm{cm}^{-2}$ was used as the resource of light illumination. Linear sweep voltammograms were measured under a bias voltage between $-0.2 \mathrm{~V}$ and 1.2 $\mathrm{V}$ versus $\mathrm{Ag} / \mathrm{AgCl}$ with a scanning rate of $10 \mathrm{mV} / \mathrm{s}$ under simulated sunlight irradiation.

\section{Results and discussion}

\subsection{Characterization of AuPd/ZnO composite samples}

The X-ray diffraction (XRD) pattern of the as-prepared $\mathrm{ZnO}$ sample is shown in Fig.1. The pure $\mathrm{ZnO}$ sample has a typical hexagonal wurtzite structure and all the diffraction peaks that appear upon nanoarrays match well with the standard ZnO diffraction pattern (JCPDS, No.70-2551). The pure 1D $\mathrm{ZnO}$ nanorod arrays have three distinct peaks at $31.8^{\circ}, 34.5^{\circ}$ and $36.3^{\circ}$, which can be attributed to (100), (002) and (101) planes, and the obtained $\mathrm{ZnO}$ nanorod arrays are detected to grow preferentially along the (002) direction. This result indicates that the $\mathrm{ZnO}$ nanorod arrays are uniform and homogeneous. 
The 1D ZnO nanorod arrays were synthesized on conducting glass substrates (FTO) by using a facile and low-cost hydrothermal method as described above. The SEM images of as-prepared pristine $\mathrm{ZnO}$ and $\mathrm{AuPd} / \mathrm{ZnO}$ photocatalysts are shown in Fig.2. It can be seen that the well-aligned $\mathrm{ZnO}$ nanorod arrays were vertically grow on the FTO substrates (Fig.2 (a)). The surface of ZnO nanorod arrays is smooth and it appears hexagonal cross section as given in Fig.2 (b). The Fig.2 (c) and (d) presents that the outside surface of the $\mathrm{ZnO}$ nanorod arrays is decorated with some nanoparticles randomly and retains the initial nanorod features compared to Fig.2 (b). At the same time, the morphology of $\mathrm{AuPd} / \mathrm{ZnO}$ is identified with the SEM images. Moreover, the XRD results proved that the $\mathrm{AuPd} / \mathrm{ZnO}$ composite sample has a good crystallinity.

The morphology and chemical composition of the sample were further analyzed by TEM. Fig.3 displays the TEM (a, b, c) and HRTEM (d and e) images of AuPd/ZnO composite. In Fig.3 (a), we can see that the $\mathrm{AuPd} / \mathrm{ZnO}$ photocatalysts show 1D microstructure after the embryonic $\mathrm{ZnO}$ nanorod arrays were treated in a certain concentration of solution. Fig.3 (b-c) shows that some nanoparticles are distributed on the pristine $\mathrm{ZnO}$ sample. Fig.3 (d-e) presents HRTEM patterns with high magnifications for the $\mathrm{AuPd} / \mathrm{ZnO}$ composite sample. The (111) interplanar distances corresponding to face-centered cubic $\mathrm{Au}$ and $\mathrm{Pd}$ nanoparticles are about $0.236 \mathrm{~nm}$ and $0.227 \mathrm{~nm}$, respectively [29-30]. By calculating from the line profile, the corresponding HRTEM image in Fig.3 (e) expressly depicts the lattice fringes with spacing of $d=0.2603 \mathrm{~nm}$ and $d=0.23 \mathrm{~nm}$, which can be indexed to the (002) plane of the hexagonal $\mathrm{ZnO}$ phase and (111) facet of AuPd alloy nanoparticles, respectively [12, 31]. As a result, HRTEM images demonstrate that the AuPd alloy exists on the surface of $\mathrm{ZnO}$ nanorod arrays. Therefore, it is expected to greatly enhance the photoelectrochemical activity of the $\mathrm{AuPd} / \mathrm{ZnO}$ sample.

The UV-vis diffuse reflectance spectra (DRS) was determined at room temperature to investigate the optical properties of as-prepared $\mathrm{ZnO}$ and $\mathrm{AuPd} / \mathrm{ZnO}$ samples, in which the wavelength range is 
300-800 $\mathrm{nm}$ as presented in Fig.4. In contrast with natural $\mathrm{ZnO}$ nanorod films, the color of the final product obtained from $\mathrm{ZnO}$ nanorods have no obvious changes. The pattern displays that pristine $\mathrm{ZnO}$ has a strong absorption in the ultraviolet region due to its wide band gap energy $(3.37 \mathrm{eV})$, while that for the target product is at $394 \mathrm{~nm}$. As the results depicted in Fig. 4, we can clearly see that the optical absorption spectra has a redshift in UV range. Referenced to the reported literature, the bulk $\mathrm{ZnO}$ sample only shows strong absorption in the ultraviolet region which is centered at $378 \mathrm{~nm}$ [32]. Compared with pure $1 \mathrm{D} \mathrm{ZnO}$ nanorod arrays, the AuPd decorated $\mathrm{ZnO}$ has similar absorption edge in shape and slight increase in absorbance intensity. The DRS results prove that the composite sample could improve the light absorption intensity after the introduction of AuPd alloy nanoparticles, which maybe have the potential of enhancing photoactivity.

Furthermore, X-ray photoelectron spectroscopy (XPS) was applied to obtain the chemical compositions and the binding states of $\mathrm{AuPd} / \mathrm{ZnO}$ nanorod arrays. The XPS spectrum survey illustrates that $\mathrm{O}, \mathrm{Zn}, \mathrm{Au}, \mathrm{Pd}$ elements are presented in the $\mathrm{AuPd} / \mathrm{ZnO}$ photocatalyst as given in Fig.5 (a), and the $\mathrm{C} 1 \mathrm{~s}$ is used as a reference to calibrate the peak shifts. As shown in the high resolution XPS spectra of O 1s (Fig.5 (c)), the peak located at $531.2 \mathrm{eV}$ is indexed to $\mathrm{O}$ atoms which exists in $\mathrm{ZnO}$ lattice [33]. Fig.5 (d) shows the high-resolution XPS spectrum of $\mathrm{Zn} 2 \mathrm{p}$, the peaks centered at $1022 \mathrm{eV}$ and $1045 \mathrm{eV}$ are corresponding to $\mathrm{Zn} 2 \mathrm{p}_{3 / 2}$ and $\mathrm{Zn} 2 \mathrm{p}_{1 / 2}$, respectively, which implies the existence of $\mathrm{Zn}$ element in $\mathrm{ZnO}$ [34]. As presented in Fig.5 (e), the peaks located at $82.8 \mathrm{eV}$ and $86.4 \mathrm{eV}$ can be indexed to $\mathrm{Au} 4 \mathrm{f}_{7 / 2}$ and $\mathrm{Au} 4 \mathrm{f}_{5 / 2}$, which display a negative shift compared to that of $\mathrm{Au} / \mathrm{TiO}_{2}$ [35]. There is also a slight downshift in comparison to the peaks in the cross-linked $\mathrm{Au} / \mathrm{ZnO}$ nanowire arrays, which may be ascribed to the formation of AuPd bimetallic alloy $[19,36]$. Moreover, it should be noted that other peaks centered at $88.65 \mathrm{eV}$ and $90.8 \mathrm{eV}$ are ascribed to $\mathrm{Zn} 3 \mathrm{p}_{3 / 2}$ and $\mathrm{Zn} 3 \mathrm{p}_{1 / 2}$, similar to previous literature [19, 37]. Fig.5 (f) gives the XPS spectra of Pd 3d, and shows two peaks centered at $335 \mathrm{eV}$ 
and $340.3 \mathrm{eV}$, which are corresponding to the $\mathrm{Pd} 3 \mathrm{~d}_{5 / 2}$ and $\mathrm{Pd} 3 \mathrm{~d}_{3 / 2}$, respectively. Consequently, the above XPS analysis together with the XRD and TEM results data have clearly proved that AuPd/ZnO photocatalyst was successfully prepared by using a simple method, as well as in a facile conditions.

\subsection{Photoelectrochemical performances of AuPd/ZnO composite samples}

To further reveal the effect of AuPd alloy particles, a three-electrodes PEC system was applied to detect the photoelectrochemcial performances with as-obtained $1 \mathrm{D} \mathrm{ZnO}$ nanorod arrays and the AuPd/ZnO samples using $\mathrm{Na}_{2} \mathrm{SO}_{4}$ as electrolyte $(0.5 \mathrm{M})$ under simulated sunlight illumination. Fig.6 shows the photocurrent density of the two products under the applied potential from $-0.2 \mathrm{~V}$ to $1.2 \mathrm{~V}$ versus $\mathrm{Ag} / \mathrm{AgCl}$. In dark condition, the current density of as-obtained two samples can be neglected, while much higher photocurrent density can be achieved under simulated sunlight condition. As it can be seen, the current density of the $\mathrm{AuPd} / \mathrm{ZnO}$ sample which derives from $\mathrm{ZnO}$ nanorod arrays is higher than that of pure $\mathrm{ZnO}$ arrays, indicating higher efficiency for PEC water splitting. Fig.6 presents that the photocurrent density of $\mathrm{ZnO}$ nanorods array is about $0.41 \mathrm{~mA} \cdot \mathrm{cm}^{-2}$ at $0.787 \mathrm{~V}$ versus $\mathrm{Ag} / \mathrm{AgCl}$, while the photocurrent density of $\mathrm{AuPd} / \mathrm{ZnO}$ photocatalysit is $0.98 \mathrm{~mA} \cdot \mathrm{cm}^{-2}$ at $0.787 \mathrm{~V}$ versus $\mathrm{Ag} / \mathrm{AgCl}$. It is noticed that the photocurrent intensity is about 2.4 times to the pure $\mathrm{ZnO}$ nanorod arrays after introducing AuPd, and the result implies the important role of AuPd alloy in enhancing the PEC activity. The calculated efficiencies of hydrogen generation $(\eta)$ for the $\mathrm{AuPd} / \mathrm{ZnO}$ photocatalyst and $1 \mathrm{D} \mathrm{ZnO}$ nanorod nanoarrays were estimated with the following equation [38-42]:

$$
\eta=\left[I\left(1.23-E_{\text {bias }}\right) / J_{\text {light }}\right] \times 100 \%
$$

Where $I$ is the photocurrent density $\left(\mathrm{mA} \cdot \mathrm{cm}^{-2}\right), E_{b i a s}$ is the applied potential versus RHE, and $J_{\text {light }}$ is the intensity of the solar simulated incident light $\left(100 \mathrm{~mW} \cdot \mathrm{cm}^{-2}\right)$.

The highest efficiency of $0.20 \%$ for the pure $\mathrm{ZnO}$ nanorod arrays is observed at $0.67 \mathrm{~V}$ versus $\mathrm{Ag} / \mathrm{AgCl}$ (Fig.7). In the same conditions, the supreme calculated hydrogen production efficiency value 
for $\mathrm{AuPd} / \mathrm{ZnO}$ photocatalyst was $0.52 \%$ at $0.61 \mathrm{~V}$ versus $\mathrm{Ag} / \mathrm{AgCl}$, and the highest efficiency is about $160 \%$ higher than that of pristine $1 \mathrm{D} \mathrm{ZnO}$ nanorod arrays which indicating a notable enhancement compared to pure $\mathrm{ZnO}$. In conclusion, the $\mathrm{AuPd}$ alloy nanoparticles decorated $\mathrm{ZnO}$ nanorod arrays as a PEC electrode is more suitable for water splitting in comparison to $\mathrm{ZnO}$ samples.

In addition, to further investigate the stability of AuPd bimetallic nanoparticles decorated $\mathrm{ZnO}$ nanorod arrays, linear sweep voltammograms were measured after $\mathrm{C}-\mathrm{V}$ scanning for 1 and 5 cycles under $\mathrm{AM} 1.5 \mathrm{G}$ illumination using $\mathrm{AuPd}$ decorated $\mathrm{ZnO}$ and $\mathrm{ZnO}$ nanorod arrays as typical photoelectrode. The current intensity of 5 th is about $0.78 \mathrm{~mA} \cdot \mathrm{cm}^{-2}$ at $0.787 \mathrm{~V}$ versus $\mathrm{Ag} / \mathrm{AgCl}$ which was about $20 \%$ lower than that of 1 cycle (Fig.8). I-V characteristic measurement also verifies an improved efficiency of $\mathrm{AuPd} / \mathrm{ZnO}$ composite structure (5th) by $91.2 \%$ compared to $\mathrm{ZnO}$ nanorod arrays electrode. Based on the above results, it can be observed that there is slight decrease in the efficiency of photoelectrochemical water splitting activity.

\subsection{Photocatalytic mechanism discussion}

It has been proved that the Au-Pd bimetallic nanoparticles can enhance the photocatalytic activity and increase the rate of photodegradation of $\mathrm{ZnO}$ nanorods [31]. And it is believed that According to the results analysts above, a possible mechanism for improvement in the PEC performance of the $\mathrm{AuPd} / \mathrm{ZnO}$ sample was proposed and displayed in Fig.9. It is well known that preventing the quickly recombination of photogenerated electron-hole pairs, enhancing separation efficiency and prolonging the lifetime of charge carriers could significantly improve the photoactivity. Vertically well-aligned 1D $\mathrm{ZnO}$ nanorod arrays can reflect unabsorbed lights back to $\mathrm{ZnO}$ nanoarrays and AuPd nanoparticles, and enhance the utilization of UV-visible light. In this process, the $\mathrm{ZnO}$ nanorods absorb more photons and generate a large number of free electrons and holes in the conduction band (CB) and the valence band (VB), respectively. What's more, vertical $\mathrm{ZnO}$ nanorod arrays on the FTO substrate can directly 
transport the photo-generated electrons with a high speed, which is beneficial to the carrier transport properties [43]. Simultaneously, the hot electrons generated from surface plasmons photo-excitation of AuPd alloy nanoparticles are injected into the conduction band of $\mathrm{ZnO}$. Finally, the electrons move to the Pt counter electrode through the FTO substrate and participate in the reduction of water to form $\mathrm{H}_{2}$. The holes in the $\mathrm{VB}$ of $\mathrm{ZnO}$ are exhausted by water oxidation to generate $\mathrm{O}_{2}$ under the applied potential $[12,44]$. Finally, the significantly enhanced efficiency of PEC water splitting can be attributed to synergistic effect between $1 \mathrm{D} \mathrm{ZnO}$ nanorod arrays and AuPd alloy nanoparticles. However, deeper investigations for the enhancement mechanism is undergoing in our lab.

\section{Conclusions}

In conclusion, the $\mathrm{AuPd} / \mathrm{ZnO}$ composite structure was vertically synthesized on FTO substrate using $1 \mathrm{D} \mathrm{ZnO}$ nanorod arrays as basement via a facile and efficient hydrothermal method. Among the several bimetallic alloy materials, AuPd alloy nanoparticles are especially attractive owing to their excellent catalytic activity and high stability [45-47]. The optical properties of $\mathrm{AuPd} / \mathrm{ZnO}$ were investigated by PEC experiment, the photocurrent density was up to $0.98 \mathrm{~mA} \cdot \mathrm{cm}^{-2}$ at $0.787 \mathrm{~V}$ vs $\mathrm{Ag} / \mathrm{AgCl}$, which exhibited a higher photoactivity than that of the pure $\mathrm{ZnO}$ nanorod arrays in PEC water splitting process. The reasons for the enhancement of catalyst activity can be summarized as the following: Firstly, the AuPd bimetallic nanoparticle has higher photocatalytic activity owing to the existence of the plasmonic properties of $\mathrm{Au}$, catalytic behavior of $\mathrm{Pd}$ [27] which making the electron on the AuPd alloy with a higher energetic state [48]. Secondly, AuPd alloy nanoparticles on the $\mathrm{ZnO}$ nanorod surface can improve the light utilization efficiency by reflect unabsorbed photons back to $\mathrm{ZnO}$ nanorod arrays [49-50]. Thirdly, $\mathrm{ZnO}$ nanorods grown on the conductive glass substrate can directly transport the excited electrons to outer electrode, which takes full advantage of the excellent charge transport property of $\mathrm{ZnO}$ nanorods [51]. As described above, the photoactivity of $\mathrm{AuPd} / \mathrm{ZnO}$ sample 
was significantly enhanced owing to the synergistic effect between $1 \mathrm{D} \mathrm{ZnO}$ nanorod arrays and AuPd alloy nanoparticles. Further studies to elucidate the mechanism are in progress.

\section{Acknowledgements}

This work was financially supported by the National Science Foundation of China (Grant No. 21003157, 21273285 and 51572295), Beijing Nova Program (Grant No. 2008B76), and Science Foundation of China University of Petroleum, Beijing (Grant No. KYJJ2012-06-20).

\section{References}

[1] Y. He, D. Li, J. Chen, Y. Shao, J. Xian, X. Zheng, P. Wang, $\mathrm{Sn}_{3} \mathrm{O}_{4}$ : a novel heterovalent-tin photocatalyst with hierarchical 3D nanostructures under visible light, RSC Adv. 4 (2014) 1266-1269.

[2] X. Wang, D. Liu, S. Song, H. Zhang, Pt@CeO 2 Multicore@Shell Self-Assembled Nanospheres: Clean Synthesis, Structure Optimization, and Catalytic Applications, J. Am. Chem. Soc. 135 (2013) $15864-15872$.

[3] M. Ni, M.K.H. Leung, D.Y.C. Leung, K. Sumathy, A review and recent developments in photocatalytic water-splitting using for hydrogen production, Renewable and Sustainable Energy Reviews 11 (2007) 401-425.

[4] Y. Li, T. Takata, D. Cha, K. Takanabe, T. Minegishi, J. Kubota, K. Domen, Vertically Aligned $\mathrm{Ta}_{3} \mathrm{~N}_{5}$ Nanorod Arrays for Solar-Driven Photoelectrochemical Water Splitting, Adv Mater. 25 (2013) 125-131.

[5] S. Dahl, I. Chorkendorff, Solar-fuel generation: Towards practical implementation, Nat Mater. 11 (2012) 100-101. 
[6] S. Xie, X. Lu, T. Zhai, W. Li, M. Yu, C. Liang, Y. Tong, Enhanced photoactivity and stability of carbon and nitrogen co-treated $\mathrm{ZnO}$ nanorod arrays for photoelectrochemical water splitting, $\mathrm{J}$ Mater Chem. 22 (2012) 14272-14275.

[7] X. Zhang, Y. Liu, Z. Kang, 3D Branched ZnO Nanowire Arrays Decorated with Plasmonic Au Nanoparticles for High-Performance Photoelectrochemical Water Splitting, ACS Appl. Mater. Interfaces 6 (2014) 4480-4489.

[8] C. Chen, W. Ma, J. Zhao, Semiconductor-mediated photodegradation of pollutants under visible-light irradiation, Chemical Society Reviews 39 (2010) 4206-4219.

[9] Z. Zhang, L. Zhang, M.N. Hedhili, H. Zhang, P. Wang, Plasmonic Gold Nanocrystals Coupled with Photonic Crystal Seamlessly on $\mathrm{TiO}_{2}$ Nanotube Photoelectrodes for Efficient Visible Light Photoelectrochemical Water Splitting, Nano Lett. 13 (2013) 14-20.

[10] Q. Zhang, T.P. Chou, B. Russo, S.A. Jenekhe, G. Cao, Polydisperse Aggregates of ZnO Nanocrystallites: A Method for Energy-Conversion-Efficiency Enhancement in Dye-Sensitized Solar Cells, Adv. Funct. Mater. 18 (2008) 1654-1660.

[11] C. Liu, Z. Liu, Y. Li, Z. Liu, Y. Wang, L. E, J. Ya, N. Gargiulo, D. Caputo, Enhanced visible-light-responsive photocatalytic property of $\mathrm{CdS}$ and $\mathrm{PbS}$ sensitized $\mathrm{ZnO}$ nanocomposite photocatalysts, Materials Science and Engineering: B 177 (2012) 570-574.

[12] C. Zhang, M. Shao, F. Ning, S. Xu, Z. Li, M. Wei, D.G. Evans, X. Duan, Au nanoparticles sensitized ZnO nanorod@nanoplatelet core-shell arrays for enhanced photoelectrochemical water splitting, Nano Energy 12 (2015) 231-239.

[13] J. Zhou, Z. Wang, A. Grots, X. He, Electric field drives the nonlinear resonance of a piezoelectric nanowire, Solid State Commun. 144 (2007) 118-123.

[14] S. Khanchandani, S. Kundu, A. Patra, A.K. Ganguli, Shell Thickness Dependent Photocatalytic 
Properties of ZnO/CdS Core-Shell Nanorods, J. Phys. Chem. C 116 (2012) 23653-23662.

[15] M. Ahmad, J. Zhu, ZnO based advanced functional nanostructures: synthesis, properties and applications, J. Mater. Chem. 21 (2011) 599-614.

[16] X.M. Shuai, W.Z. Shen, A Facile Chemical Conversion Synthesis of $\mathrm{ZnO} / \mathrm{ZnS}$ Core/Shell Nanorods and Diverse Metal Sulfide Nanotubes, J. Phys. Chem. C 115 (2011) 6415-6422.

[17] Y. Du, B. Xu, T. Fu, M. Cai, F. Li, Y. Zhang, Q. Wang, Near-Infrared Photoluminescent $\operatorname{Ag}_{2} \mathrm{~S}$ Quantum Dots from a Single Source Precursor, J. Am. Chem. Soc. 132 (2010) 1470-1471.

[18] C. Liu, Z. Liu, Y. Li, J. Ya, L. E, L. An, CdS/PbS co-sensitized ZnO nanorods and its photovoltaic properties, Appl. Surf. Sci. 257 (2011) 7041-7046.

[19] T. Wang, B. Jin, Z. Jiao, G. Lu, J. Ye, Y. Bi, Photo-directed growth of Au nanowires on ZnO arrays for enhancing photoelectrochemical performances, J. Mater. Chem. A 2 (2014) 15553-15559.

[20] T. Wang, B. Jin, Z. Jiao, G. Lu, J. Ye, Y. Bi, Electric field-directed growth and photoelectrochemical properties of cross-linked Au-ZnO hetero-nanowire arrays, Chem. Commun. 51 (2015) 2103-2106.

[21] T. Wang, Z. Jiao, T. Chen, Y. Li, W. Ren, S. Lin, G. Lu, J. Ye, Y. Bi, Vertically aligned ZnO nanowire arrays tip-grafted with silver nanoparticles for photoelectrochemical applications, Nanoscale 5 (2013) 7552-7557.

[22] S. Mondal, A. Samanta, B.B. Dhar, R.N. Devi, Encapsulation of ultra small metal clusters in silica: Evolution of the concept of nanoreactors and the case of $\mathrm{Ag}-\mathrm{Pd} @ \mathrm{SiO}_{2}$ alloy catalyst, Catalysis Today 251 (2015) 114-120.

[23] J. Xu, T. Zhao, Z. Liang, L. Zhu, Facile Preparation of AuPt Alloy Nanoparticles from Organometallic Complex Precursor, Chem. Mater. 20 (2008) 1688-1690.

[24] G. Liang, L. He, M. Arai, F. Zhao, The Pt-Enriched PtNi Alloy Surface and its Excellent Catalytic Performance in Hydrolytic Hydrogenation of Cellulose, Chem. Sus. Chem. 7 (2014) 1415-1421. 
[25] L. Guczi, A. Beck, A. Horváth, Z. Koppány, G. Stefler, K. Frey, I. Sajó, O. Geszti, D. Bazin, J. Lynch, AuPd bimetallic nanoparticles on $\mathrm{TiO}_{2}$ : XRD, TEM, in situ EXAFS studies and catalytic activity in CO oxidation, J. Mol. Catal. A: Chem. 204-205 (2003) 545-552.

[26] M. Guo, P. Diao, S. Cai, Hydrothermal growth of perpendicularly oriented ZnO nanorod array film and its photoelectrochemical properties, Appl. Surf. Sci. 249 (2005) 71-75.

[27] R.S. Moakhar, A. Kushwaha, M. Jalali, G.K.L. Goh, A. Dolati, M. Ghorbani, Enhancement in solar driven water splitting by Au-Pd nanoparticle decoration of electrochemically grown $\mathrm{ZnO}$ nanorods, J. Appl. Electrochem. 46 (2016) 819-827.

[28] R. Su, R. Tiruvalam, A.J. Logsdail, Q. He, C.A. Downing, M.T. Jensen, N. Dimitratos, L. Kesavan, P.P. Wells, R. Bechstein, H.H. Jensen, S. Wendt, C.R.A. Catlow, C.J. Kiely, G.J. Hutchings, F. Besenbacher, Designer Titania-Supported Au-Pd Nanoparticles for Efficient Photocatalytic Hydrogen Production, ACS Nano 8 (2014) 3490-3497.

[29] C. Han, L. Wu, L. Ge, Y. Li, Z. Zhao, AuPd bimetallic nanoparticles decorated graphitic carbon nitride for highly efficient reduction of water to $\mathrm{H}_{2}$ under visible light irradiation, Carbon, 92 (2015) $31-40$.

[30] Y. Xin, L. Wu, L. Ge, C. Han, Y. Li, S. Fang, Gold-palladium bimetallic nanoalloy decorated ultrathin $2 \mathrm{D} \mathrm{TiO}_{2}$ nanosheets as efficient photocatalysts with high hydrogen evolution activity, J. Mater. Chem. A 3 (2015) 8659-8666.

[31] B. Panigrahy, D.D. Sarma, Enhanced photocatalytic efficiency of AuPd nanoalloy decorated ZnO-reduced graphene oxide nanocomposites, RSC Adv. 5 (2015) 8918-8928.

[32] J.J. Schneider, R.C. Hoffmann, J. Engstler, O. Soffke, W. Jaegermann, A. Issanin, A. Klyszcz, A Printed and Flexible Field-Effect Transistor Device with Nanoscale Zinc Oxide as Active Semiconductor Material, Adv. Mater. 20 (2008) 3383-3387. 
[33] C. Battistoni, J.L. Dormann, D. Fiorani, E. Paparazzo, S. Viticoli, An XPS and Mössbauer study of the electronic properties of $\mathrm{ZnCr}_{\mathrm{x}} \mathrm{Ga}_{2-\mathrm{x}} \mathrm{O}_{4}$ spinel solid solutions, Solid State Commun. 39 (1981) 581-585.

[34] M. H. Yeh, L. Y. Lin, C. Y. Chou, C. P. Lee, H. M. Chuang, R. Vittal, K. C. Ho, Preparing core-shell structure of $\mathrm{ZnO} @ \mathrm{TiO}_{2}$ nanowires through a simple dipping-rinse-hydrolyzation process as the photoanode for dye-sensitized solar cells, Nano Energy 2 (2013) 609-621.

[35] A. Cybula, J.B. Priebe, M.-M. Pohl, J.W. Sobczak, M. Schneider, A. Zielińska-Jurek, A. Brückner, A. Zaleska, The effect of calcination temperature on structure and photocatalytic properties of $\mathrm{Au} / \mathrm{Pd}$ nanoparticles supported on $\mathrm{TiO}_{2}$, Applied Catalysis B: Environmental 152-153 (2014) 202-211.

[36] T. H. Yang, L. D. Huang, Y. W. Harn, C. C. Lin, J. K. Chang, C. I. Wu, J. M. Wu, High Density Unaggregated $\mathrm{Au}$ Nanoparticles on ZnO Nanorod Arrays Function as Efficient and Recyclable Photocatalysts for Environmental Purification, Small 9 (2013) 3169-3182.

[37] S. Maroie, G. Haemers, J.J. Verbist, Surface oxidation of polycrystalline $\alpha(75 \% \mathrm{Cu} / 25 \% \mathrm{Zn})$ and $\beta(53 \% \mathrm{Cu} / 47 \% \mathrm{Zn})$ brass as studied by XPS: Influence of oxygen pressure, Applications of Surface Science 17 (1984) 463-467.

[38] M.G. Walter, E.L. Warren, J.R. McKone, S.W. Boettcher, Q. Mi, E.A. Santori, N.S. Lewis, Solar Water Splitting Cells, Chem. Rev. 110 (2010) 6446-6473.

[39] K. Guo, Z. Liu, Y. Wang, Y. Zhao, Y. Xiao, J. Han, Y. Li, B. Wang, T. Cui, Fabrication of $\mathrm{ZnO} / \mathrm{SrTiO}_{3}$ nanoarrays and its photoelectrochemical performances, Int. J. Hydrogen Energy 39 (2014) 13408-13414.

[40] Y. Zhao, Y. He, D.-B. Xiong, W. Ran, Z. Liu, F. Gao, Dual template synthesis and photoelectrochemical performance of 3-D hierarchical porous zinc oxide, Int. J. Hydrogen Energy 
39 (2014) 13486-13490.

[41] Z. Liu, Y. Wang, B. Wang, Y. Li, Z. Liu, J. Han, K. Guo, Y. Li, T. Cui, L. Han, C. Liu, G. Li, PEC electrode of $\mathrm{ZnO}$ nanorods sensitized by $\mathrm{CdS}$ with different size and its photoelectric properties, Int. J. Hydrogen Energy 38 (2013) 10226-10234.

[42] J. Han, Z. Liu, K. Guo, X. Zhang, T. Hong, B. Wang, AgSbS 2 modified ZnO nanotube arrays for photoelectrochemical water splitting, Applied Catalysis B: Environmental 179 (2015) 61-68.

[43] J. Han, Z. Liu, K. Guo, B. Wang, X. Zhang, T. Hong, High-efficiency photoelectrochemical electrodes based on $\mathrm{ZnIn}_{2} \mathrm{~S}_{4}$ sensitized $\mathrm{ZnO}$ nanotube arrays, Applied Catalysis B: Environmental 163 (2015) 179-188.

[44] Z. Bai, X. Yan, Z. Kang, Y. Hu, X. Zhang, Y. Zhang, Photoelectrochemical performance enhancement of $\mathrm{ZnO}$ photoanodes from $\mathrm{ZnIn}_{2} \mathrm{~S}_{4}$ nanosheets coating, Nano Energy 14 (2015) $392-400$.

[45] X. Zhou, Y. Huang, W. Xing, C. Liu, J. Liao, T. Lu, High-quality hydrogen from the catalyzed decomposition of formic acid by Pd-Au/C and Pd-Ag/C, Chem. Commun. 30 (2008) 3540-3542.

[46] Y. Mizukoshi, K. Sato, T.J. Konno, N. Masahashi, Dependence of photocatalytic activities upon the structures of $\mathrm{Au} / \mathrm{Pd}$ bimetallic nanoparticles immobilized on $\mathrm{TiO}_{2}$ surface, Applied Catalysis $\mathrm{B}$ : Environmental 94 (2010) 248-253.

[47] X. Yang, C. Huang, Z. Fu, H. Song, S. Liao, Y. Su, L. Du, X. Li, An effective Pd-promoted gold catalyst supported on mesoporous silica particles for the oxidation of benzyl alcohol, Applied Catalysis B: Environmental 140-141 (2013) 419-425.

[48] S. Dhara, P.K. Giri, On the origin of enhanced photoconduction and photoluminescence from $\mathrm{Au}$ and Ti nanoparticles decorated aligned ZnO nanowire heterostructures, J. Appl. Phys. 110 (2011) 124317 
[49] Y. Li, Z. Liu, Y. Wang, Z. Liu, J. Han, J. Ya, ZnO/CuInS 2 core/shell heterojunction nanoarray for photoelectrochemical water splitting, Int. J. Hydrogen Energy 37 (2012) 15029-15037.

[50] J. Han, Z. Liu, K. Guo, J. Ya, Y. Zhao, X. Zhang, T. Hong, J. Liu, High-Efficiency $\mathrm{AgInS}_{2}$-Modified $\mathrm{ZnO}$ Nanotube Array Photoelectrodes for All-Solid-State Hybrid Solar Cells, ACS Appl. Materials and Interfaces 6 (2014) 17119-17125.

[51] M. Law, L.E. Greene, J.C. Johnson, R. Saykally, P. Yang, Nanowire dye-sensitized solar cells, Nat. Mater. 4 (2005) 455-459. 


\section{Figure Captions:}

Fig.1 XRD patterns of 1D ZnO nanorod arrays and 70-2551 Zincite, syn.

Fig.2 SEM images of (a), (b) $\mathrm{ZnO}$ and (c), (d) $\mathrm{AuPd} / \mathrm{ZnO}$ photocatalysts.

Fig.3 TEM images (a, b, c) and HRTEM ( $d$ and e) images of AuPd/ZnO composite.

Fig.4 UV-vis diffuses reflectance spectra of pure $\mathrm{ZnO}$ and $\mathrm{AuPd} / \mathrm{ZnO}$ composite samples.

Fig.5 (a) Wide XPS spectrum and high resolution XPS spectra of as-prepared AuPd/ZnO sample: (a,b)

C 1s; (c) O 1s; (d) Zn 2p; (e) Au 4f and Zn 3p; (f) Pd 3d.

Fig.6 Current Density-Potential curves of the 1D ZnO nanorod arrays and AuPd/ZnO samples under AM 1.5 G illumination $\left(100 \mathrm{~mW} / \mathrm{cm}^{2}\right)$ and dark condition.

Fig.7 Photoconversion efficiency curves of $\mathrm{ZnO}$ and $\mathrm{AuPd} / \mathrm{ZnO}$.

Fig.8 Linear sweep voltammograms of as-prepared $\mathrm{AuPd} / \mathrm{ZnO}$ composite with different cycle times.

Fig.9 A proposed mechanism for the improvement of the PEC performance. 


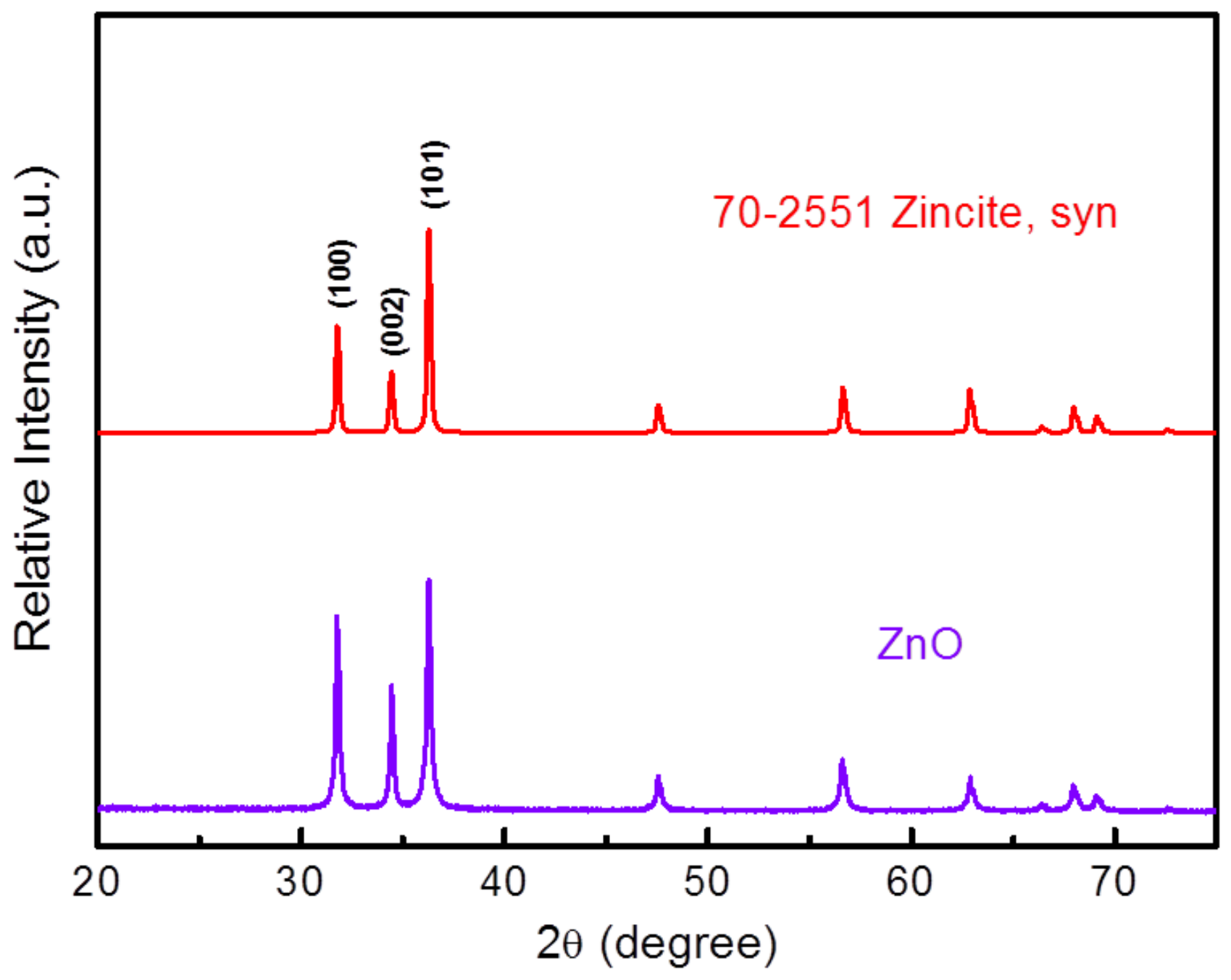

Fig.1 XRD patterns of 1D ZnO nanorod arrays and 70-2551 Zincite, syn. 

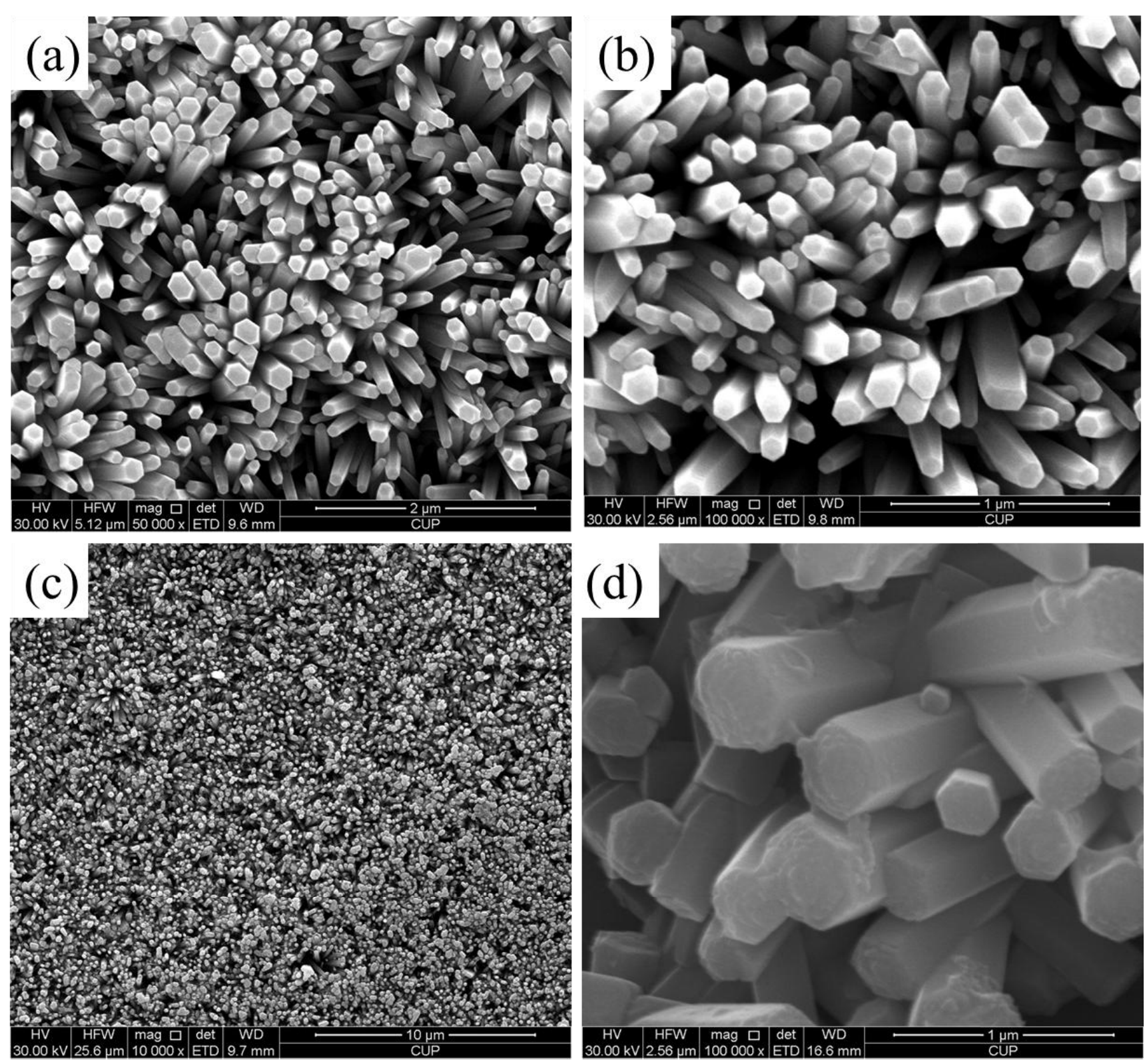

Fig.2 SEM images of (a), (b) $\mathrm{ZnO}$ and (c), (d) AuPd/ZnO photocatalysts. 

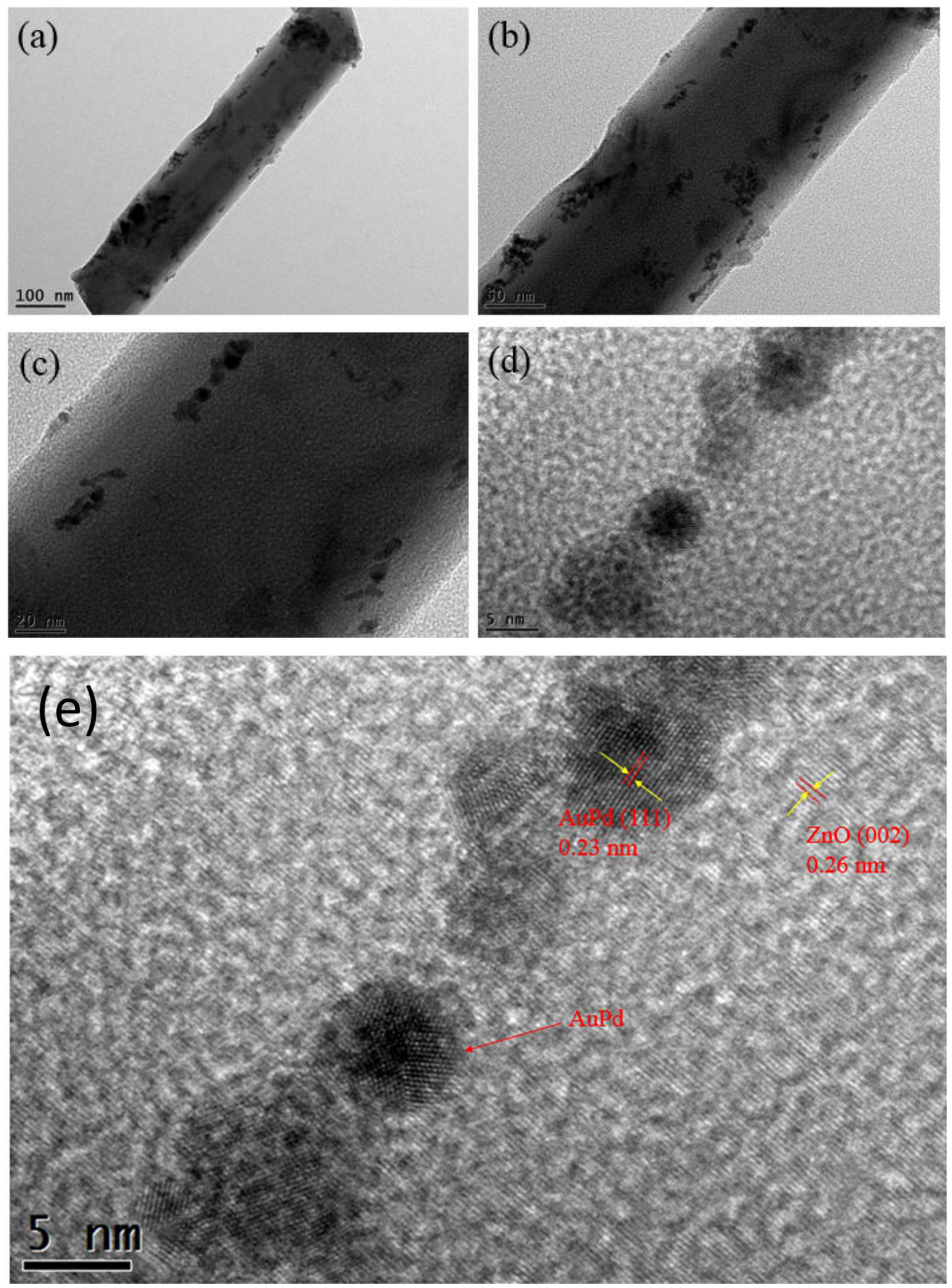

Fig.3 TEM images (a, b, c) and HRTEM ( $d$ and e) images of AuPd/ZnO composite. 


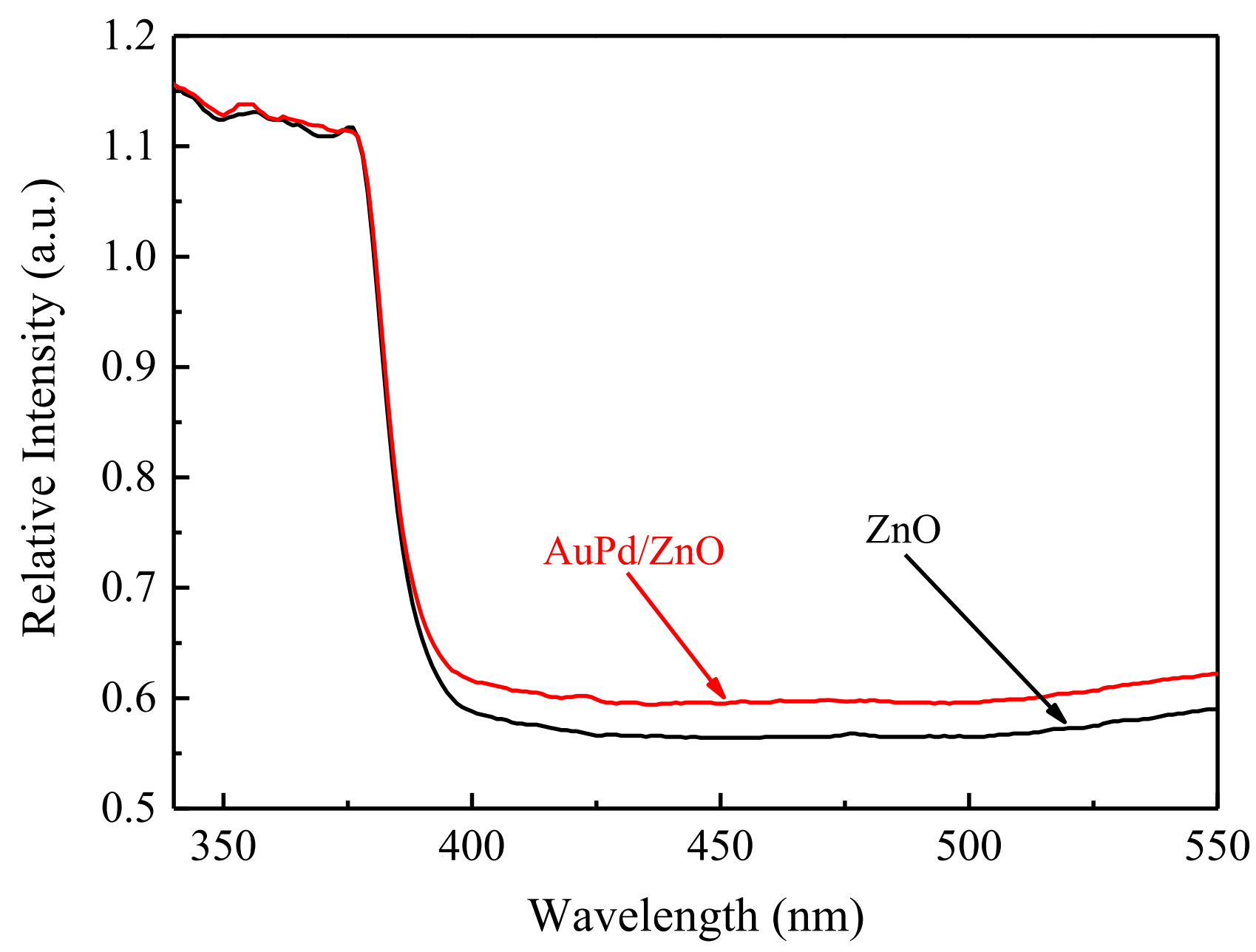

Fig.4 UV-vis diffuses reflectance spectra of pure $\mathrm{ZnO}$ and $\mathrm{AuPd} / \mathrm{ZnO}$ composite samples. 

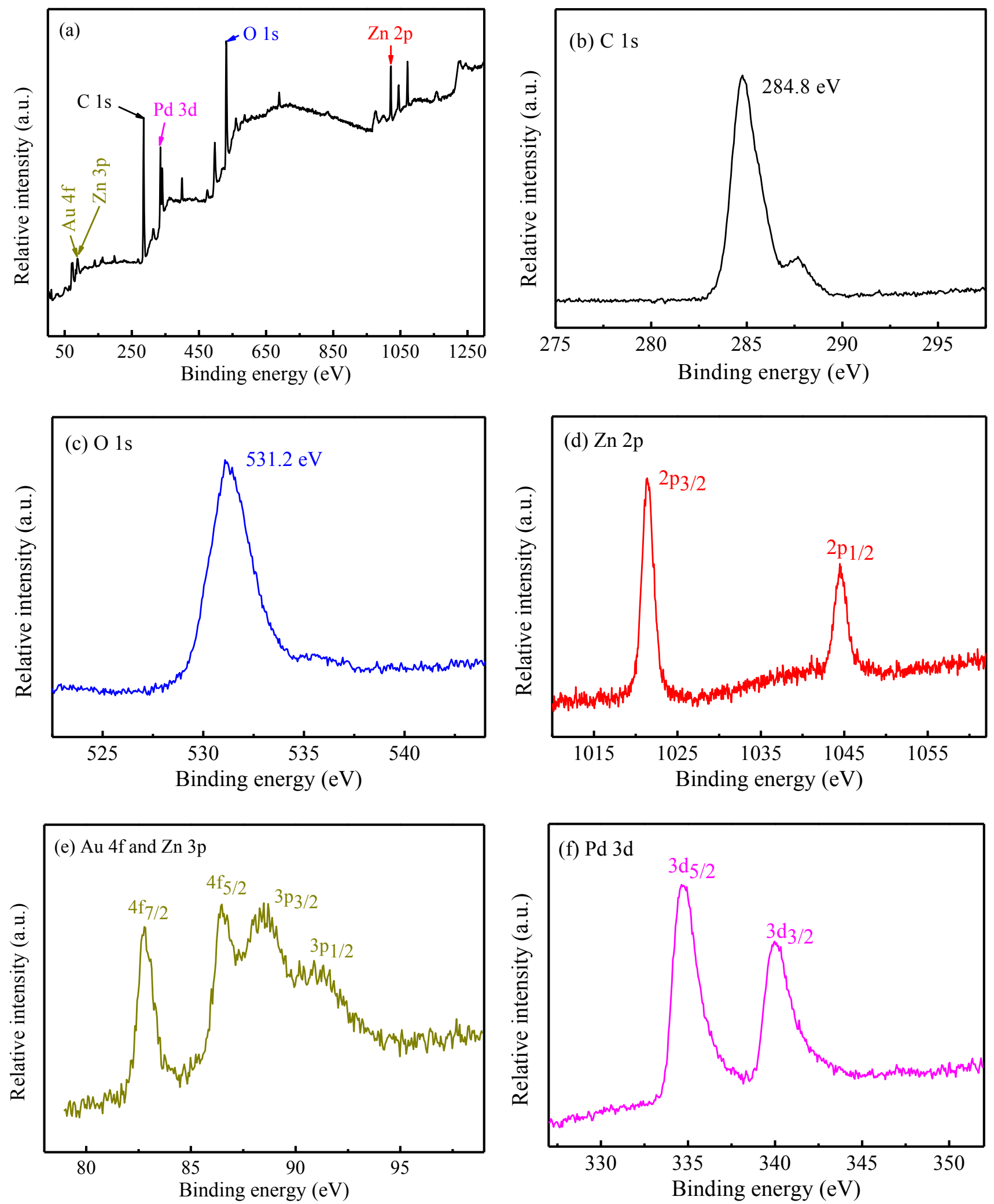

Fig.5 (a) Wide XPS spectrum and high resolution XPS spectra of as-prepared AuPd/ZnO sample: (b) C 1s; (c) O 1s; (d) Zn 2p; (e) Au 4f and Zn 3p; (f) Pd 3d. 


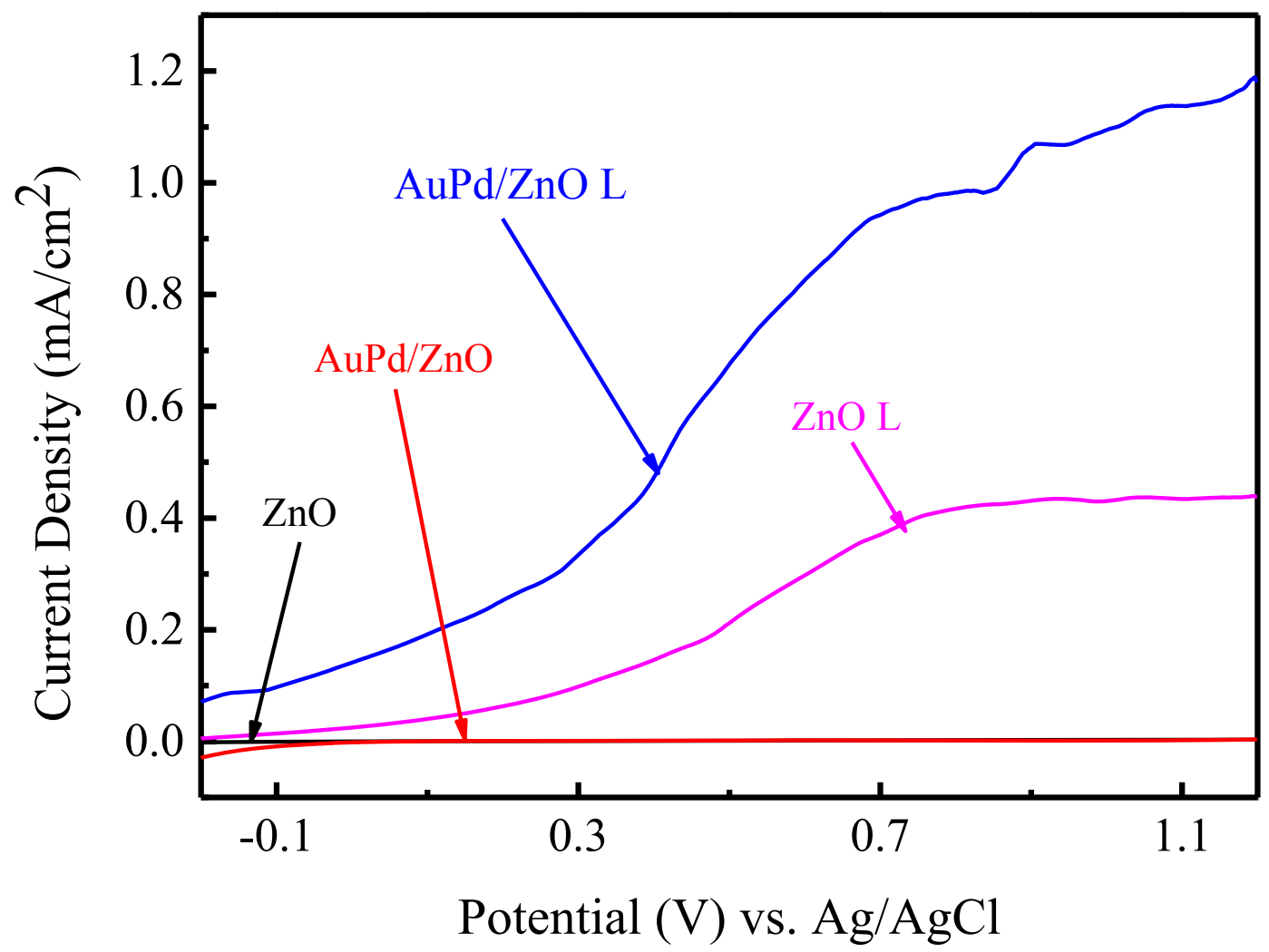

Fig.6 Current Density-Potential curves of the 1D ZnO nanorods and AuPd/ZnO samples under AM 1.5 G illumination $\left(100 \mathrm{~mW} / \mathrm{cm}^{2}\right)$ and dark condition. 


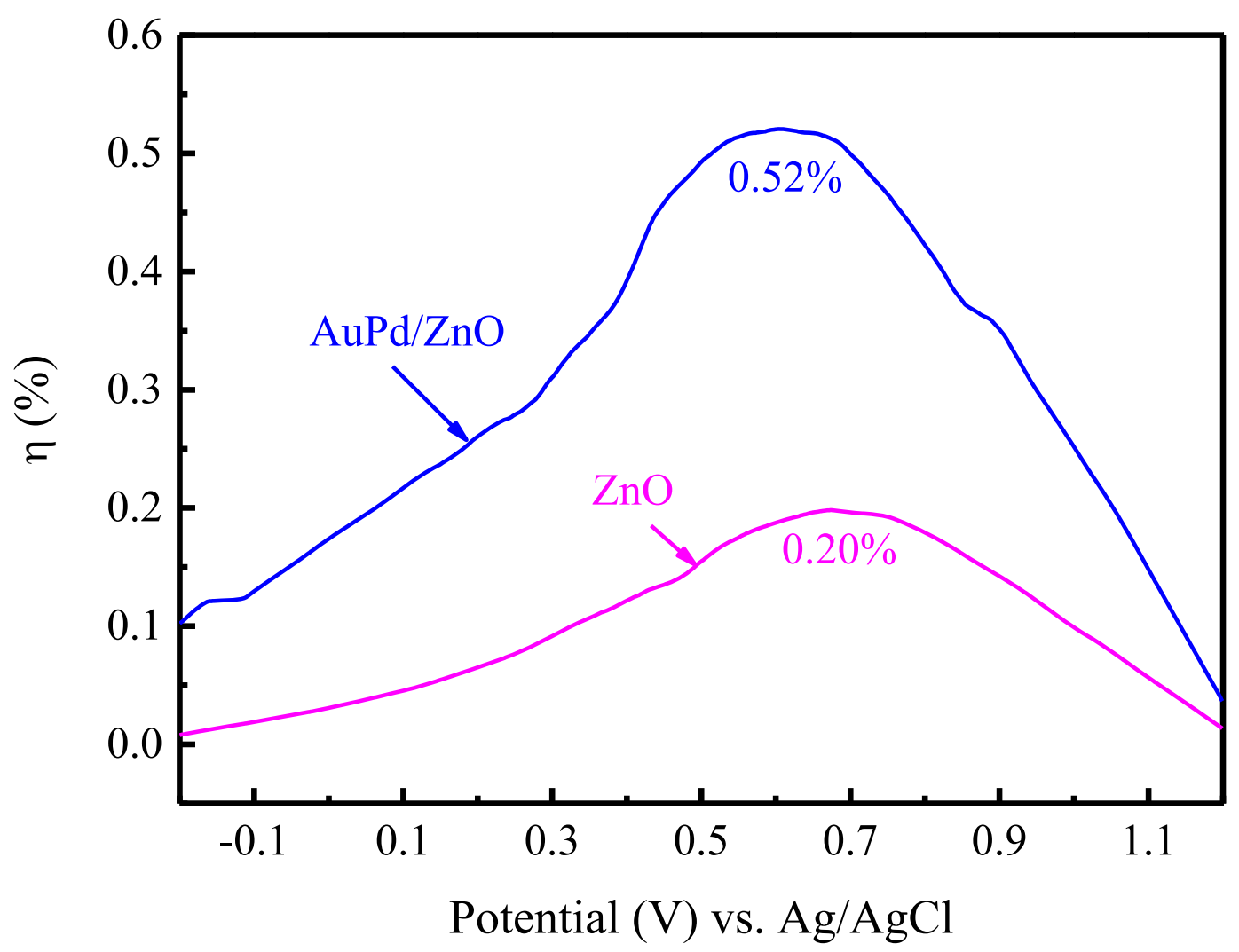

Fig.7 Photoconversion efficiency curves of $\mathrm{ZnO}$ and $\mathrm{AuPd} / \mathrm{ZnO}$. 


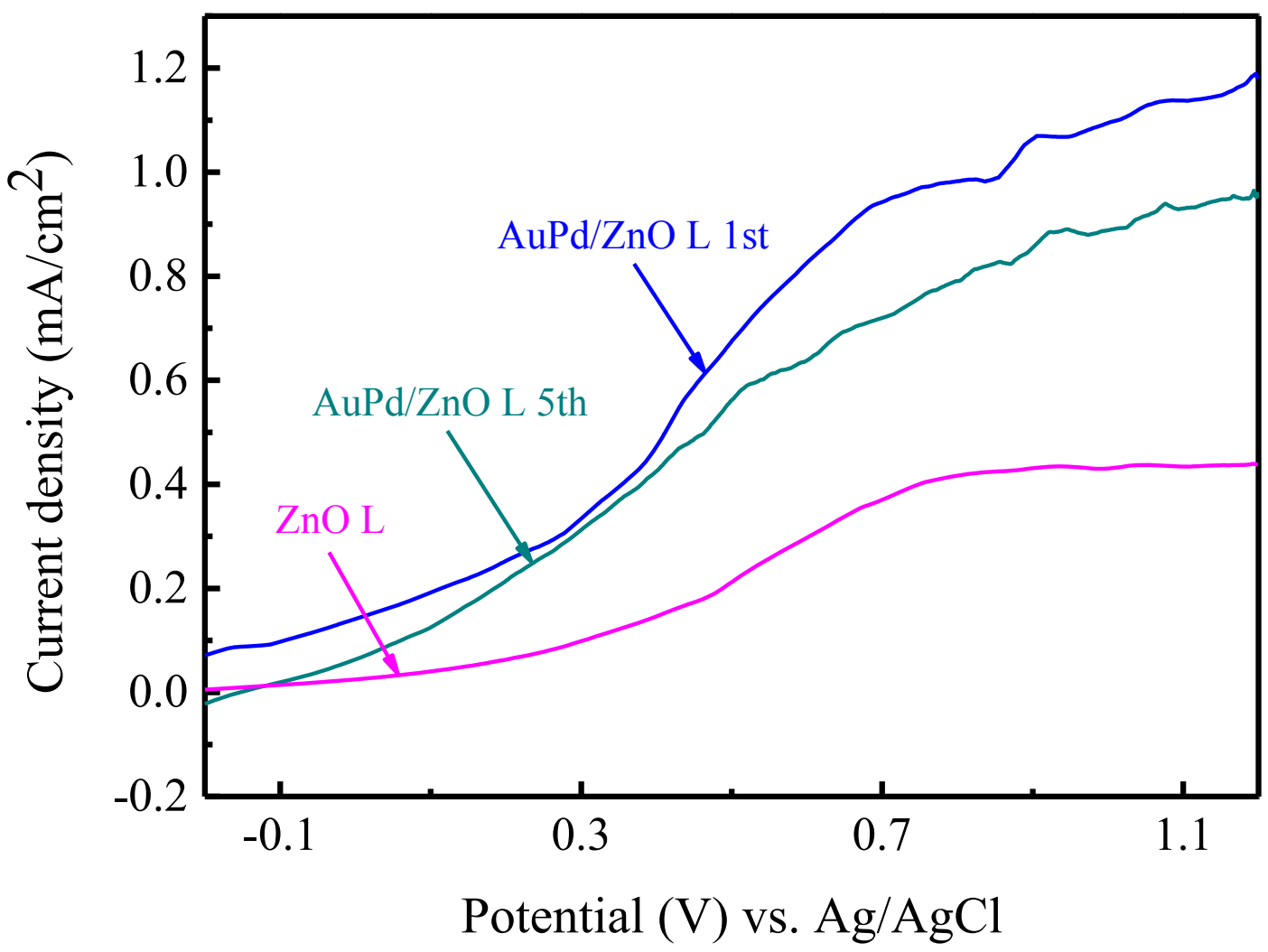

Fig.8 Linear sweep voltammograms of as-prepared $\mathrm{AuPd} / \mathrm{ZnO}$ composite with different cycle times. 


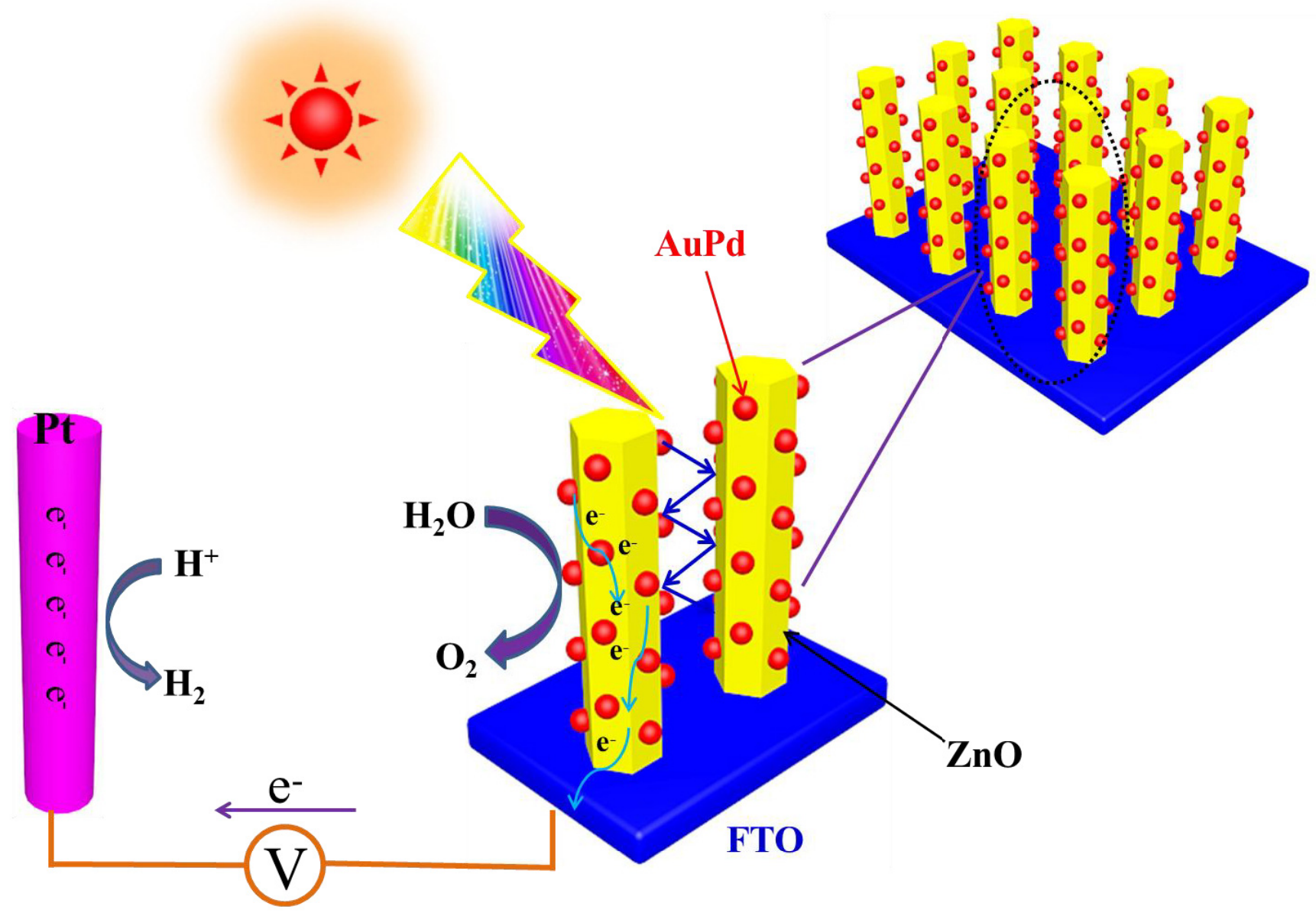

Fig.9 A proposed mechanism for the improvement of the PEC performance. 


\section{Graphical Abstract}
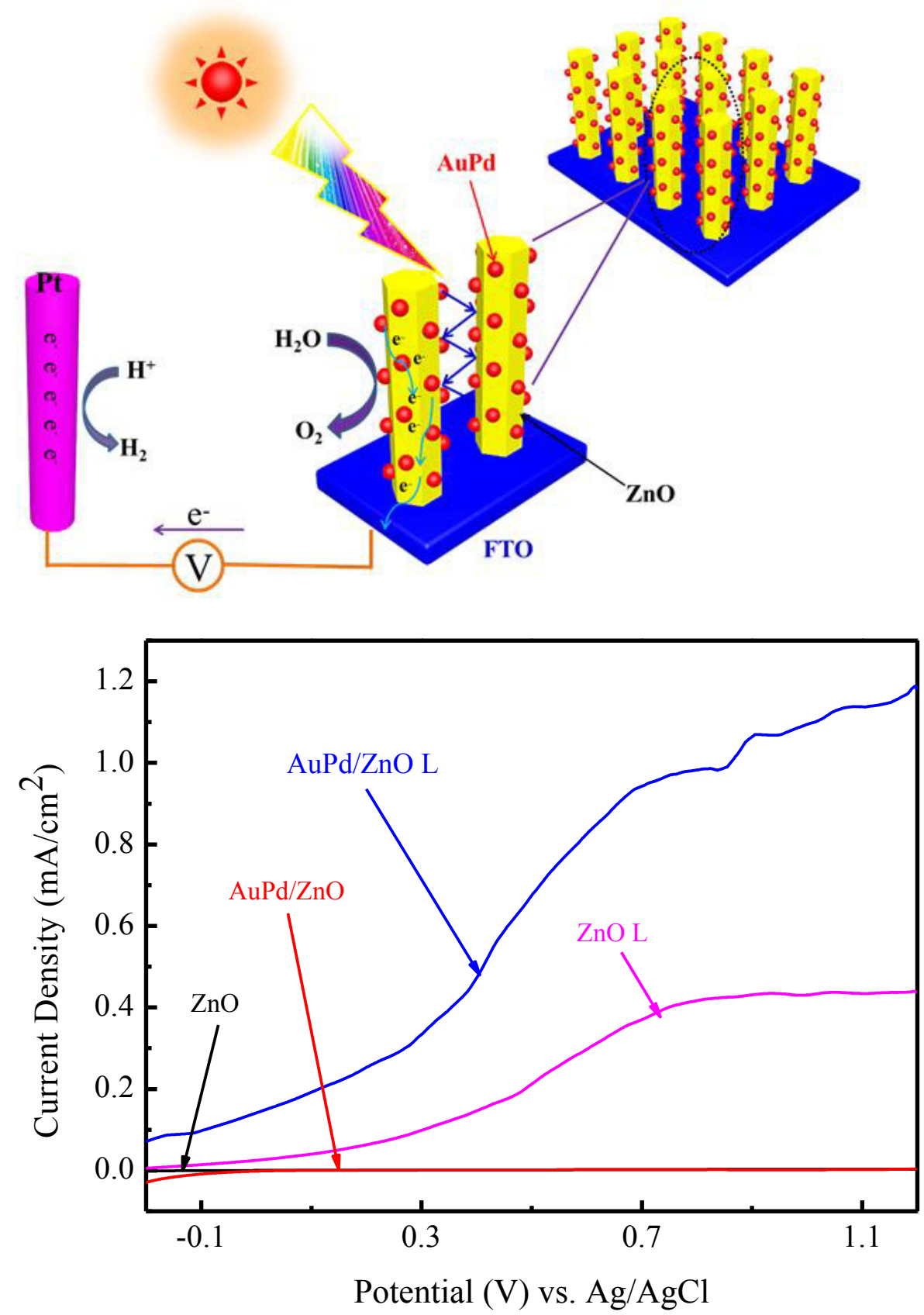